\title{
XVIII. Some remarks on the use of nitrat of silver, for the detection of minute portions of arsenic
}

\author{
Alex. Marcet M.D. F.R.S.
}

To cite this article: Alex. Marcet M.D. F.R.S. (1813) XVIII. Some remarks on the use of nitrat of silver, for the detection of minute portions of arsenic , Philosophical Magazine Series 1, 41:178, 121-124, DOI: $10.1080 / 14786441308638714$

To link to this article: http://dx.doi.org/10.1080/14786441308638714

曲 Published online: 27 Jul 2009.

Submit your article to this journal $₫$

Џll Article views: 2

Q View related articles $\longleftarrow$ 
quite as exhilarating when cold as when it is taken hot, why should it not be made to supply the place of those pernicious drams of spirituous liquors, which do so much harm?

"Hall a pint of good cold coffee, properly sweetened, whic would not cost more than balf a pint of porter, wou d be a much more refreshing and exhilarating draught; and would no doubt be incomparably more nourishing.

"How mucb then must it be preferable to a dram of gin!

"The advantages and disadvantages to agriculture and conunerce, which would arise from the introduction of a new beverage for supplying the place of malt liquors and ardent spiriis distilled from grain, must be estimated and balanced by those whose knowledge of political ceconomy fits them for determining these must intricate and importanit questions."

This ingenious Essay also presents descriptions (with engravings) of elegant coffee urns; but as these are destined for the opulent, we beg to refer for further particulars to the Count's Eighteenth Essay.

XVIII. Some Remarks on the Use of Nitrat of Silver, for the Detection of minute Portions of Arsenic. By ALEX. Marcet, M.D. F.R.S. one of the Physicians to Guy's Hospital*.

$I_{N}$ the interesting account of the poisonous effects of arsenic, presented to the Society by Dr. Roget, and published in the second volume of the Medico-Chirurgical Transactions $f$, the author has recommended, for the detection of this poison, a test which I pointed out to him, and which, from a variety of experimerits which we tried together, with a view to ascertain its comparative merits, we were induced to consider as the most effectual of all the tests hitherto used for that purpose. The method consists simply in adding in succession, to the fluid suspected to contain arsenic, minute quantities of solutions of ammonia and of nitrat of sifver; by which means, if the smallest quantity of arsenic be present, a dense yellow precipitate will be produced.

* From the third volume of the Medico-Chirurgical Transactions, published by the Medical and Chirurgical Society of L.ondon.

+ I take this opportunity of staring, at Dr. Roget's request, that the patient, whose case he there related, completely recovered fier hedik, and has remained well ever since. 
All the particulars respecting this mode of detection having been fully stated by Dr. Roget, with such references to former writers on the subject as the case required, it would be quite superfuous to enter into any further detail on this head. My object in resuming the subject, the practical importance of which need not be pointed out, is to communicate to the Society the result of an inquiry which 1 have made on the nature of the yellow precipitate, the appearance of which is assumed as denoting the psesence of arsenic, and ro answer some objections which have been made aguinst this test by Mr. Sylvester, of Derby, in a paper on metallic poisons, recently published in Nicholson's Journal*.

The yellow compound in question has the following properties :

If, after being well washed with distilled water, it be suffered to stand for some time in an open vessel, it gradually passes to a brown colour; but it does not, like nitrat of silver, become black on continuing this exposure.

It is readily soltible in dilute nitric acid. It also dissolves on adding an excess of ammonia at the moment of its formation; but after it has been separated and dried, it is no longer sensibly soluble in ammonia.

If a small quantity of this precipitate be exposed to the heat of a lamp on a slip of laminated platina, a white smoke arises from it, and metaltic silver remains attached to the platina. The reduction of the silver, in the form of a globule, is still more distinct and striking, if a little carbonaceous matter be mixed with the precipitate, and the blowpipe applied.

When the yellow precipitate, inclosed in a tube, is exposed to the heat of a lamp, the white smoke condenses on the cold part of the tube, in minute octohedral crystals of arsenious acid.

It appears, therefore, that the precipitate in question is a combination of white arsenic (arsenious acid) and silver, or an arsenite of silver; and it is inferred that its formation, when ammonia and nitrat of silver are added to a mixture containing arsenious acid, is owing to a double elective decomposition of the arsenite of ammonia by the nitrat of silver, in consequence of which arsenitc of silver is formed, and separates as an insoluble precipitate from the nitrat of ammonia shich remains in the solation. The addition of ammonia is necessary, because arsenic acid alone cannot

* aiciudson s Journal for December 1812, vol. xxxiii. p. 306. 
decompose nitrat of silver; but in Fowler's solution, in which the arsenic is already combined with an alkali, the decomposition takes place at once, without any addition of ammonia. The fixed alkalies, therefore, can answer a similar purpose; but ammonia has this advantage, that it does not, when added singly, decompose nitrat of silver, - a circumstance which, in using the fixed alkalies, might occasion some confusion*.

With regard to Mr. Sylvester's objection, I shall, previously to my offering any remarks upon it, state it in his own words : " If ever muriatic acid be present," says this gentleman, "s the test is then wholly useless, as a muriat of silver will be immediately formed, and the yellow compound, said to be so unequivocal in its indication of arsenic, of course be prevented from appearing."

This danger of ambiguity, however, though applying in some degree to the process in question, and well deserving to be noticed, will be found to have been greatly overrated; and there are such easy and obvious means by which this ambiguity can be entirely removed, that it can make no solid objection to the utility of the test.

There cannot be the least doubt, as Mr. S. observes, but that whenever nitrat of silver is added to a solution containing muriatic acid, a precipitate of muriat of silver must be the consequence. But if the nitrat of silver be added in excess, the arsenite of silver is also thrown down by the intervention of ammonia, and a mixed precipitate of luna cornea and arsenite of silver is obtained, which partakes more or less of the yellow colour of the latter, according to the proportion of the two salts.

If to this dubious precipitate a few drops of dilute nitric acid be added, the arsenite of silver is instantly dissolved, and the muriat of silver, which is insoluble, immediately resumes its peculiar density and whiteness. If a little ammonia be now added to the clear fluid, the yellow precipitate appears in the most distinct manner, and becomes even more characteristic from a comparison with the white pre-

* It is necessary, as Dr. Roget has observed in the paper already quoted, that the quantity of ammosia should not be toolarge; for in that case the precipitate is redissolved. But, even then, it may be made to reappear, by the addition of nitric acid in sufficient quantity to saturate the alkali. In this case, however, the precipitate is not permanent, owing, I find, to its being soluble in the nitrat of ammonia which is formed in the process. Carbonat of ammonia has also the property of producing and redissolvitg the precipitate.

The fixed alkalies in excess have not the power of redissolving the preci. pitate. 
cipitate, the appearance of which differs from this in every respect.

By this method, I believe that every objection to the test will be removed; and in order to anticipate all ambiguity, and to avoid any complication or practical difficulty in its application, I would propose to modify the process in the following manner:

To the suspected fluid, previously filtered, add, first, a little dilute nitric acid, and, afterwards, nitrat of silver, till it shall cease to produce any precipitate. The muriatic acid being thus removed, whilst the arsenious acid (if any, and in whatever state, remains in the fluid, the addition of ammonia will instantly produce the yellow precipitate in its characteristic form. It is hardly necessary to add, that the quantity of ammonia must be sufficient to saturate any excess of nitric acid which the solution may contain.

XIX. On a Periscopic Camera Obscura and Microscope. By William Hrde Wollaston, M.D. Sec. R.S.*

Acthough the vicws which I originally had of the advantare to be derived from the periscopic construction of spectacies $\uparrow$ naturally suggested to me a corresponding improvement in the camera olscura, by substituting a meniscus for the double convex lens, I have hicherto deferred making it known to others, except as a subject of occasional conversation.

Since in vision with spectacles, as in common vision, the pencil of rays received by the eye in each direction is small, the superiority of that form of glass, which disposes all parts of it most nearly at right angles with the visual ray, admits of distinct demonstration: but with respect to the camera obscura, where the portion of lens requisite for sufficient illumination is of considerable magnitude, although it is evident that some improvement may be made in the distinctness of oblique images on the same principles; yet as the focus of oblique rays is far from being a definite point, the degree in which it may be improved is not a fit subject of mathematical investigation.

I have therefore had recourse to experiments, in order to determine by what construction the field of distinct representation may be most extended; and I trust the result will be acceptable to this Society. I shall take the same

- From the Philosophical Transactions for 1812, part ii.

Thil, Mag, vol, xwii. Nicholson's Journal, vii, 143.

opportunity 